\title{
Microstructural strength of tidal soils - a rheometric approach to develop pedotransfer functions
}

\author{
Nina Stoppe ${ }^{*}$, Rainer Horn \\ Institute of Plant Nutrition and Soil Science, Christian-Albrechts-University Kiel, Hermann-Rodewaldstr. 2, D-24118 Kiel, Germany. \\ ${ }^{*}$ Corresponding author. Tel.: 0049431 880-4079. Fax: 0049431 880-2940. E-mail: n.stoppe@soils.uni-kiel.de
}

\begin{abstract}
Differences in soil stability, especially in visually comparable soils can occur due to microstructural processes and interactions. By investigating these microstructural processes with rheological investigations, it is possible to achieve a better understanding of soil behaviour from the mesoscale (soil aggregates) to macroscale (bulk soil). In this paper, a rheological investigation of the factors influencing microstructural stability of riparian soils was conducted. Homogenized samples of Marshland soils from the riparian zone of the Elbe River (North Germany) were analyzed with amplitude sweeps (AS) under controlled shear deformation in a modular compact rheometer MCR 300 (Anton Paar, Germany) at different matric potentials. A range physicochemical parameters were determined (texture, $\mathrm{pH}$, organic matter, $\mathrm{CaCO}_{3}$ etc.) and these factors were used to parameterize pedotransfer functions.

The results indicate a clear dependence of microstructural elasticity on texture and water content. Although the influence of individual physicochemical factors varies depending on texture, the relevant features were identified taking combined effects into account. Thus, stabilizing factors are: organic matter, calcium ions, $\mathrm{CaCO}_{3}$ and pedogenic iron oxides; whereas sodium ions and water content represent structurally unfavorable factors. Based on the determined statistical relationships between rheological and physicochemical parameters, pedotransfer functions (PTF) have been developed.
\end{abstract}

Keywords: Rheology; Deformation; Soil micromechanics; Structural stability; Structure degradation; Pedotransfer functions.

\section{INTRODUCTION}

The tidal part of the Elbe River (North Germany) has been modified several times over the past decades by dredging and riverbank reinforcement to meet cargo vessel requirements. This has changed the hydromorphology of the Tidal Elbe estuary by an enhanced volume of sediment being transported upstream and a more pronounced gradient in salinity (Bergemann, 1995; Freitag et al., 2007; Garniel and Mierwald, 1996). Through specific hydraulic-engineering structures, dynamic processes in stream margins and riparian zones are suppressed. To return the Tidal Elbe estuary to a more natural state, anthropogenic structures such as artificial rip-rap revetments could be removed and dynamic processes driven by the tide enhanced. However, the impact of these interventions to tidal soil stability is unknown and requires investigation.

The quantification of structural stability is a central field of research, as soil structure possesses many functions e.g. resistance against deformation and erosion, and there have been ambitious projects and discussions on it for several decades as reviewed by e.g. Bronick and Lal (2005) or Warkentin (2008). In classical soil mechanics, the stability of soil structure is often characterized by examining compression and/or shear behavior. These analyses on the mesoscale provide information about the reaction of the regarded total soil volume towards stresses at defined boundary conditions. Parameters such as precompression stress $(P c)$, angle of internal friction $(\phi)$ and cohesion $(c)$ at the aggregate or bulk soil scale provide valuable information about mechanical response, but cannot identify the causes of mechanical stability (Hartge and Horn, 2016). The reasons for different strength properties, particularly in visually comparable soils that to the eye have similar colour, texture and structure, can manifest at the microscale from interparticle to microaggregate interactions. Knowledge of the processes at the microscale has been made possible in recent years by rheological studies of natural soils (e.g. Ghezzehei and Or, 2001;
Holthusen, 2010; Markgraf and Horn, 2009; Pértile et al., 2016; Torrance, 1999). Key drivers of rheological behavior identified in these studies are soil organic matter and varying electrolyte concentrations (e.g. Carotenuto et al., 2015; Holthusen et al., 2012c; Markgraf et al., 2012b). In tidal soils, Markgraf et al. (2012a) found differences in the rheology and therefore the microstructural stability between natural, Na-affected and cultivated gypsum amended in a Salic Tidalic Fluvisol from Sevilla, Spain. They found dispersing effects due to repulsive forces related to $\mathrm{Na}^{+}$under natural, sodic-saline conditions, and aggregating effects from gypsum amelioration based on attractive forces for $\mathrm{Ca}^{2+}$. In a more humid climate, the repulsive forces of $\mathrm{Na}^{+}$and the strengthening effect of $\mathrm{Ca}^{2+}$ were observed in the micro-mechanical strength of soils from two sites of the riparian zone of the Elbe River estuary, taking salinity gradient and soil maturation into account (Baumgarten et al., 2012).

Recent studies confirm that many further physicochemical parameters affect the rheological response of soils including: soil texture and water content (Jeong et al., 2010; Markgraf et al., 2006), cation exchange capacity and electric conductivity (EC) (Baumgarten et al., 2012; Markgraf and Horn, 2006), carbonate content and $\mathrm{pH}$ (Markgraf et al., 2012a) as well as iron (hydr)oxides (Markgraf and Horn, 2007). However, the combined effect of physicochemical parameters influencing the microstructural stability has received limited attention. For tidal soils, such information is extremely important to assess the potential risks and benefits of interventions to alter the hydrodynamic properties of rivers or to remove past anthropogenic structures that affect tidal response. To address this gap in knowledge, this study compares physicochemical factors to rheological response of tidal soils. Samples are taken from a natural gradient in salinity and sodicity along the estuary and from chronosequences of Salic Fluvisols to Calcaric Fluvisols. By exploring a wide range of physicochemical parameters we identify the statistically significant factors and attempt to parameterize them into pedotransfer functions. 
The aim is to facilitate a mathematical estimate of the rheological parameter integral $z$, which has been introduced by Markgraf and Horn (2009) and quantifies the microstructural stiffness.

\section{MATERIAL AND METHODS Soil samples}

Twenty-two sites along the North German Elbe estuary were chosen to provide a gradient in salinity and sodicity (Fig. 1).

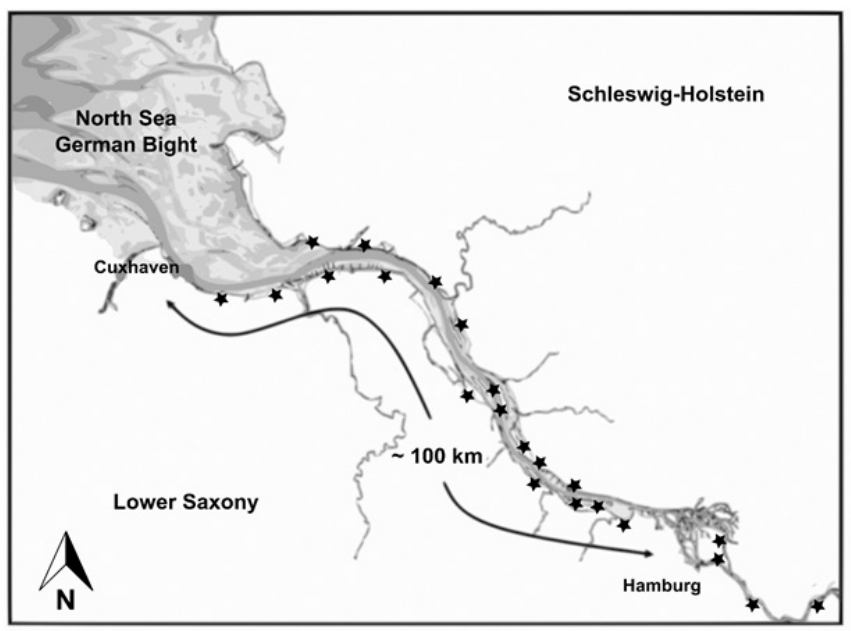

Fig. 1. The Elbe estuary sampling locations: stars depict the sites (modified after Freitag et al. (2007)).

At each site, three soil pits were dug in the embankment foreland at three elevations in relation to the mean water levels: profile 1 above mean high tide (MHWL), where commonly grassland had developed; profile 2 in the range of MHWL with partly extensive reed vegetation and profile 3 below MHWL with sparse vegetation (Fig. 2). Disturbed samples were taken from each profile at defined depths: in profile 1 at $10,30,50$ and $70 \mathrm{~cm}$; in profile 2 at 10,30 and $50 \mathrm{~cm}$; in profile 3 at 10 and $30 \mathrm{~cm}$ beneath ground level. After transferring the soil to the laboratory in properly sealed plastic bags, the samples were air dried, homogenized with a pestle and passed through a sieve with a mesh size of $2 \mathrm{~mm}$.

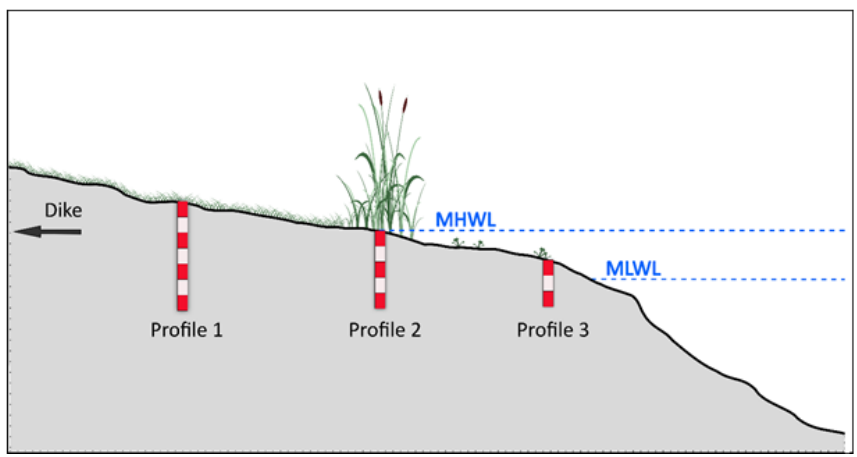

Fig. 2. Schematic illustration of the sampling design in the embankment foreland of the Elbe estuary. (MHWL = mean high water level, MLWL = mean low water level).

\section{Standard physicochemical analyses}

The laboratory analyses described in the following were performed according to Blume et al. (2011) and Schlichting et al.
(1995). Sieved soil material was was mixed at 1:2.5 (w/w) with $0.01 \mathrm{M} \mathrm{CaCl}_{2}$ to determine $\mathrm{pH}$ and deionized water to determine electric conductivity $(E C)$. Particle size distribution was analyzed by sieving and sedimentation after destroying soil organic matter with $\mathrm{H}_{2} \mathrm{O}_{2}(30 \%)$, and dissolving calcite $\left(\mathrm{CaCO}_{3}\right)$ by $\mathrm{HCl}$. Total soil carbon was measured by means of finely ground soil material, which was ashed in a Ströhlein apparatus based on the principle of coulometry. The content of $\mathrm{CaCO}_{3}$ was determined according to Scheibler's method by gas volumetric determination of the released $\mathrm{CO}_{2}$. The difference between inorganic and total carbon is equivalent to the organic C. Exchangeable cations were extracted by $0.1 \mathrm{M} \mathrm{BaCl}_{2}$. Concentrations of $\mathrm{Ca}^{2+}, \mathrm{Mg}^{2+}, \mathrm{K}^{+}$and $\mathrm{Na}^{+}$were measured against standard solutions using a flame AAS system. The total amount of pedogenic iron oxides $\left(\mathrm{Fe}_{d}\right)$, which develop during pedogenese, were analyzed by extraction with $0.3 \mathrm{M} \mathrm{Na}$-citrate solution, $1 \mathrm{M} \mathrm{NaHCO}_{3}$ solution and Na-dithionite according to the method described by Mehra and Jackson (1960). The iron concentration was determined by atomic absorption spectrometry.

\section{Rheometry}

Amplitude sweeps (AS) with controlled shear deformation were conducted with a modular compact rheometer MCR 300 (Anton Paar, Ostfildern, Germany) with a profiled $25 \mathrm{~mm}$ diameter parallel-plate measuring system at a plate distance of 4 $\mathrm{mm}$ in oscillating mode. The configurations of the tests were carried out in accordance with Markgraf (2006) (Table 1), since these configurations already have shown good performance and reproducibility in previous studies (e.g. Ajayi Ayodele and Horn, 2016; Baumgarten et al., 2013; Holthusen et al., 2010, $2012 b$ ). However, some settings vary from conventional rheological test settings. To consider the greatest possible particle/ cluster size of the sieved soil material, the measuring gap is fixed to $4 \mathrm{~mm}$ as a compromise, because it is the smallest possible plate distance to produce reliable rheological data without removing a significant portion of primary particles and breakdown of microaggregate structures that are of interest. The frequency is kept constant at $0.5 \mathrm{~Hz}$ - common values are around $1.6 \mathrm{~Hz}$ - to ensure that the determined rheological parameters $\left(G^{\prime}, G^{\prime \prime}\right)$ describe the actual structural character of the soil and not a more inflexible structure because of faster oscillation, which may occur at frequencies 5-10 times higher (Mezger, 2014).

Table 1. Configuration of amplitude sweeps with controlled shear deformation (after Markgraf (2006)).

\begin{tabular}{ll}
\hline Parameter & \\
\hline Measuring system & $\begin{array}{l}\text { crosshatched parallel-plate system, } \\
\text { diameter }=25 \mathrm{~mm}\end{array}$ \\
Plate distance $(h)$ & $h=4 \mathrm{~mm}$ \\
Shear deformation $(\gamma)$ & continuous deformation ramp with \\
& $\gamma=0.0001$ to $100 \%$ \\
Frequency $(f)$ & $f=0.5 \mathrm{~Hz}(\omega=\pi 1 / \mathrm{s})$ \\
Temperature $(T)$ & $T=20^{\circ} \mathrm{C}$ (regulated by Peltier unit) \\
Measuring points & 30 pts. \\
Test duration & appr. $15 \mathrm{~min}$. \\
\hline
\end{tabular}

Air dried, homogenized and sieved $(<2 \mathrm{~mm})$ samples from all sites and depths were repacked into stainless steel cylinders $\left(45 \mathrm{~cm}^{3}\right)$ to a standard bulk density of $1.4 \mathrm{Mg} \mathrm{m}^{-3}$. Afterwards, the repacked samples were capillary saturated with deionized water to achieve quasi-saturated conditions $(0 \mathrm{kPa})$. Subsequently, a portion of the prepared cylinders was drained and equilibrated to a matric potential of $-6 \mathrm{kPa}$ on ceramic plates. 
Repacked soil samples from profile 1 were additionally equilibrated to a matric potential of $-15 \mathrm{kPa}$.

For the rheological measurement, a small amount of soil was taken with a spatula from each cylinder and put on the fixed measuring plate of the rheometer. After lowering the upper plate to the defined measuring gap $(4 \mathrm{~mm})$ automatically, the normal force was checked to maintain an undisturbed quasielastic soil structure (i.e. $F_{N} \leq 12 \mathrm{~N}$ ). Operation of the rheometer, monitoring of the ASs and generation of the rheological parameters $\left(G^{\prime}, G^{\prime \prime}, \tan \delta\right.$, integral $\left.z\right)$ were carried out by the software Rheoplus/32 V3.21. Five replicates were performed per depth and dewatering state. The water content of the samples (w/w) was determined before and after each test.

\section{Loss factor tan $\delta$ and integral $z$}

Since soil can be defined as a viscoelastic substance (Markgraf, 2006), amplitude sweeps are a suitable method to investigate the structural character of soils. During amplitude sweeps soil samples experience a gradual degradation of microstructural stiffness (Fig. 3). This destruction of internal structure can be characterized by the well-established rheological parameters storage modulus $\left(G^{\prime}\right)$, loss modulus $\left(G^{\prime \prime}\right)$, their intersection at the flow point and the linear viscoelastic range $(L V E)$ where $G^{\prime}$ and $G^{\prime \prime}$ do not change with increasing applied shear deformation. Moreover, the microstructure of soils can be specified by the loss factor $\tan \delta$, which is the ratio of $G^{\prime \prime}$ to $G^{\prime}$ and describes the viscous part to the elastic part of the deformation energy. A $\tan \delta<1$ indicates that the $G^{\prime}$ is greater than $G^{\prime \prime}$, so elastic processes prevail and the soil exhibits a quasielastic behavior, i.e. applied deformation leads to full or at least partial microstructural regeneration. When $\tan \delta=1$ the flow point ("cross-over") is reached $\left(G^{\prime}=G^{\prime \prime}\right)$. If $G^{\prime}<G^{\prime \prime}$ a viscous character predominates, $\tan \delta>1$ (i.e. $G^{\prime \prime}>G^{\prime}$ ) and irreversible microstructural failure occurs (Mezger, 2014).

For further comparison of the quasi-elastic range $(\tan \delta<1)$ in absolute terms, the dimensionless area parameter integral $z$ can be used. The greater the value of integral $z$, the more elastic or rigid the soil is (Markgraf and Horn, 2009). Thus, integral $z$ quantifies the structural strength in consideration of elasticity loss due to increasing shear deformation $\gamma$ over time. The integral of $\tan \delta(\gamma)$ with $\tan \delta=1$ as the defined limit was calculated from equation (1).

$$
\int_{0.001}^{\text {"cross-over" }}(1-\tan \delta) d \gamma
$$

\section{Statistics}

All statistical analysis was done using R (Version 3.1.1) (R Developement Core Team, 2013) based on mixed models

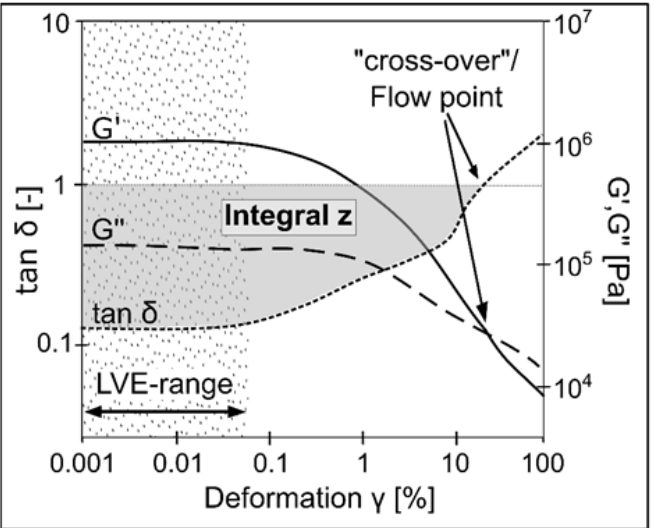

Fig. 3. Schematic result of an AST depicted as deformation function. Loss factor $\tan \delta$ equals the ratio of loss modulus to storage modulus $\left(=G^{\prime \prime} / G^{\prime}\right)$ and functions as analogue expression of elastic ( $\tan \delta \approx$ const.), viscoelastic ( $\tan \delta \leq 1$ ) or viscous behavior $(\tan \delta>1)$. For further comparison, the integral $z$ of $\tan \delta(\gamma)$ with $\tan \delta=1$ as defined limit on the ordinate can be calculated. (solid line $=G^{\prime}$, dashed line $=G^{\prime \prime}$, dotted line $=\tan \delta$, grey area $=$ integral $z$, dotted area $=L V E$-range).

(Laird and Ware, 1982; Verbeke and Molenberghs, 2008) by means of analyses of covariance and variance (ANCOVA resp. ANOVA).

First, all chemical parameters ( $\mathrm{pH}, \mathrm{EC}, \mathrm{CaCO}_{3}$ etc.) were tested on multicollinearity, as parameters that strongly correlate with one another would distort further statistical analyses. Based on this test the explanatory variables shown in Table 2 (col. 4) have been designated as non-correlated initial input parameters to run ANCOVA. Subsequently performed ANOVA permits the identification of the significant predictor variables.

\section{RESULTS \\ Rheological properties: Integral z}

The microstructural elasticities of the studied soils determined by amplitude sweeps under deformation-controlled conditions and characterized by the dimensionless area parameter integral $z$ and flow point are summarized in Table 3.

At saturation, the soil samples from profile 3, which represents the initial stage of soil maturation, had the smallest integral $z$ values (10-15). At a slightly higher elevation, usually under extensive reed vegetation (profile 2), the integral $z$ values were of the same magnitude as in profile 3 . For both profiles, loamy soil samples exhibited the greatest microstructural elasticity. This was also evident due to the shift of the flow point to a slightly greater deformation. The grassland profiles (profile 1) show a wide range of integral $z$ values from 10 to 57 at quasi saturated conditions. Again, the largest values were obtained

Table 2. Initial input parameters for statistical analyses (ANCOVA resp. ANOVA) and determined key factors significantly affecting the microstructure of the soils under study.

\begin{tabular}{|c|c|c|c|c|}
\hline Parameter & Acronym & Unit & Initial input parameters & Significant key factors $(\alpha=0.05)$ \\
\hline Electric conductivity & $E C$ & $\mathrm{mS} \mathrm{cm}^{-1}$ & $\frac{1}{x}$ & \\
\hline Organic matter & $O M$ & $\mathrm{~g} 100 \mathrm{~g}^{-1}$ & $\mathbf{x}$ & $\mathbf{x}$ \\
\hline Calcite content & $\mathrm{CaCO}_{3}$ & $\mathrm{~g} 100 \mathrm{~g}^{-1}$ & $\mathbf{x}$ & $\mathbf{x}$ \\
\hline Pedogenic iron oxides & $F e_{d}$ & $\mathrm{~g} \mathrm{~kg}^{-1}$ & $\mathbf{x}$ & $\mathbf{x}$ \\
\hline Calcium concentration & $\mathrm{Ca}^{2+}$ & $\mathrm{cmol}_{\mathrm{c}} \mathrm{kg}^{-1}$ & $\mathbf{x}$ & $\mathbf{x}$ \\
\hline Sodium concentration & $\mathrm{Na}^{+}$ & $\mathrm{cmol}_{\mathrm{c}} \mathrm{kg}^{-1}$ & $\mathbf{x}$ & $\mathbf{x}$ \\
\hline Water content & $\Theta_{g}$ & $\mathrm{w} / \mathrm{w}$ & $\mathbf{x}$ & $\mathbf{x}$ \\
\hline Depth beneath ground level & depth & $\mathrm{cm}$ & $\mathbf{x}$ & $\mathbf{x}$ \\
\hline
\end{tabular}


Table 3. Summarized results of microstructural elasticity represented by the dimensionless area parameter integral $z$ and the flow point $\gamma_{\mathrm{f}}$ given in terms of deformation (\%) (mean values with SD), considering different profiles, soil texture ${ }^{\mathrm{a}}$, salinity and three matric potentials: quasi-saturated $(0 \mathrm{kPa}),-6 \mathrm{kPa}$ and $-15 \mathrm{kPa}$. $\mathrm{NR}=$ flow point not reached.

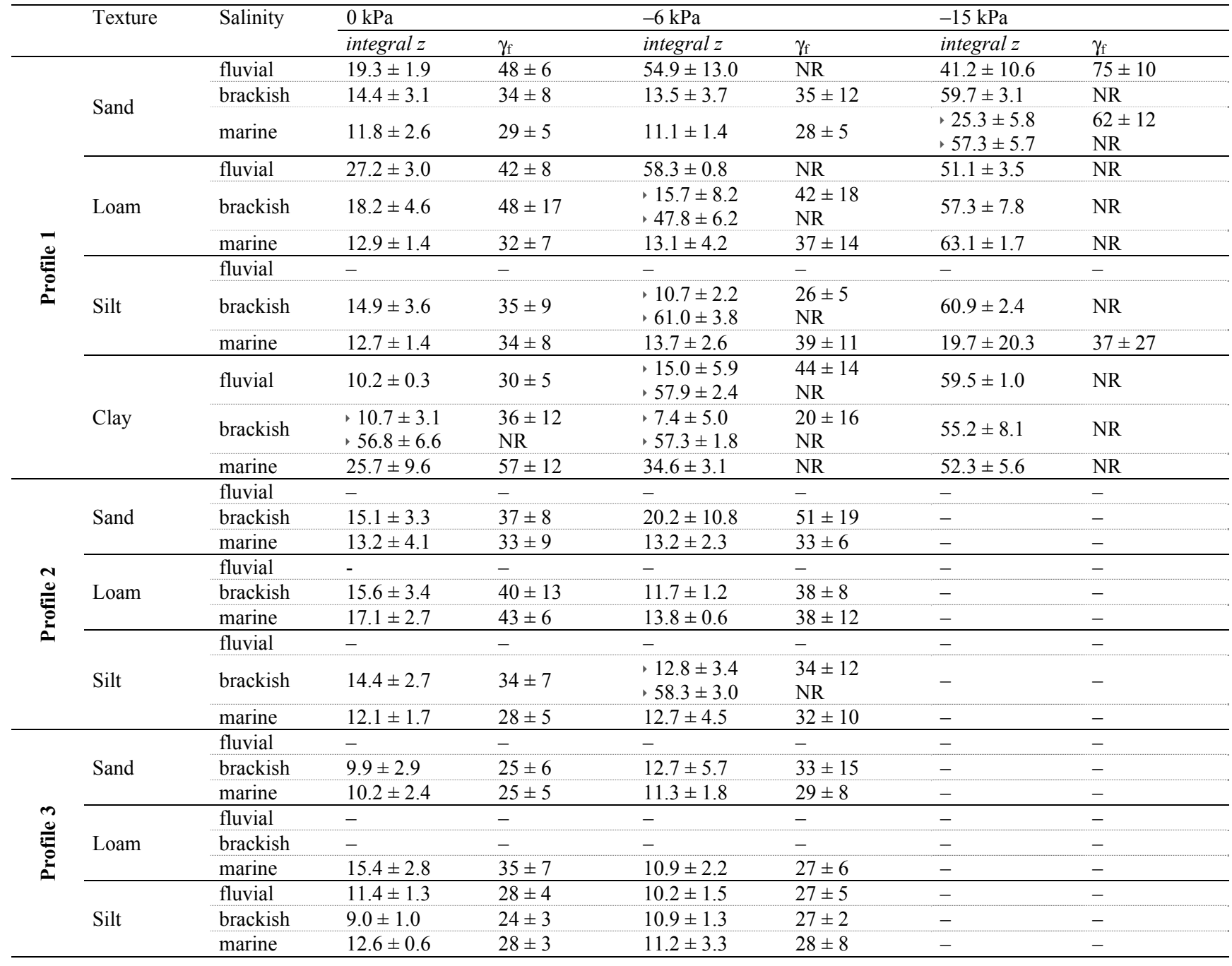

${ }^{a}$ Texture groups were defined according to the German soil texture classification (further details regarding the texture groups are available in Stoppe and Horn (2017)), thus the sand-group corresponds approx. to LS, SL and SCL after WRB, the loam-group to CL, SiCL and partly to C, SiC, SiL and L, the siltgroup approx. to SiL and $\mathrm{Si}$, the clay-group to $\mathrm{C}$ and $\mathrm{SC}$.

for loamy soil samples, but also for some clay samples in brackish waters. These clay samples did not reach the flow point during AS. Nevertheless, most samples exhibited a small microstructural elasticity and samples originating from marine sedimentation regions and clayey soil samples had the least elastic microstructure. For many soil samples it should be noted that larger integral $z$ values were reached when the flow point shifted to greater deformation values. Occasionally, deformation values at the flow point differ for similar integral $z$ values. In such cases the additional consideration of the flow point allows a more sophisticated assessment of the rheological behavior. Drainage to field capacity $(-6 \mathrm{kPa})$ induced no changes for recently deposited sediments (profile 3 ), but caused a marginally enhanced microstructural stiffness for the soil samples from profile 2, as indicated by slightly larger integral $z$ values. However, under reed vegetation, silty soil samples sometimes do not reach the flow point and therefore achieve large integral $z$ values. As under quasi-saturated conditions, the widest range of integral $z$ values was attained under grassland (11-61), but at field capacity the microstructural elasticity seemed to be intertwined with texture and the area of sedimentation: very small integral $z$ values $(<15)$ in the marine region and larger values $(>45)$ in the fluvial region. Moreover, it was notable that the values obtained at a matric potential of $-6 \mathrm{kPa}$ were characterized by variable data. In brackish waters in particular, both small and very large integral $z$ values were acquired.

At a matric potential of $-15 \mathrm{kPa}$ the integral $z$ values were usually relatively large ( $>40)$, implying a more rigid microstructure. Exceptions were silty soil samples from the marine region, which also had a large standard deviation and did not reach the flow point within the deformation range applied.

In general, the integral $z$ exhibited relatively small values and standard deviations under quasi-saturated conditions. Larger values were reached with increasing desiccation, but drainage also lead to greater deviations reflected by outliers and/or wider ranges. Although significant differences between the topsoils of profile 1 and profile 3 were determined at saturation, these differences vanished as the soils dried to field capacity. Topsoils and subsoils differed from each other under grassland and under reed for all applied matric potentials (data not shown). Rheological behavior appears to be affected less by soil maturation than the area of sedimentation and therefore physicochemical properties including texture and particle size distribution. 


\section{Texture effect and impact of drainage}

Figure 4 shows strongly generalized curves for the main texture groups (sand, loam, silt, clay) and $\tan \delta$ at different matric potentials. The curves illustrate the rheological response to oscillatory stresses for representative soil samples, which possess the average chemical features of the specific texture group.

The stiffness degradation under quasi-saturated conditions was comparable for sandy, silty and loamy soils. An increase of $\tan \delta$ at $\gamma=0.01-10 \%$ was evident and mainly due to the uppiling and re-orientation of soil particles and clusters, leading to a temporary stabilization of microstructure before its complete collapse. This re-orientation is more pronounced in sandy and silty soils than in loamy soils. Moreover, sand and silt showed a steeper increase in $\tan \delta$ after re-orientation, resulting in an earlier intersection with the $\tan \delta=1$. Loam required greater deformation to reach $\tan \delta=1$ and had a less distinct slope. In contrast, clayey soils exhibited a gradual decrease of microstructure for the entire deformation range under quasi-saturated conditions.

Desiccation to $-6 \mathrm{kPa}$ did not substantially alter the curve characteristics for loamy soils. In most cases this was also true for sandy and silty soils, but for these texture groups drainage to field capacity occasionally provoked a shift of the flow point to greater deformation, preventing deformation into the viscous regime and indicating a greater elastic microstructure measured by larger integral $z$ values. Clay retained its curve shape, depicting the gradual degradation of microstructure at field capacity. For this texture the flow point and transition into viscous flow was also not reached.

The effect of drainage was most pronounced at a matric potential of $-15 \mathrm{kPa}$. All texture groups showed curve characteristics that indicated a rigid microstructure as over a range of deformations the elastically dominated regime stayed below the $\tan \delta=1$ line.

\section{Interaction of texture and water content}

The rheological response of soils under oscillatory conditions was influenced considerably by particle size distribution and water content (see above and Fig. 5). Depending on particle size and specific surface, which increases with decreasing grain size, the water content varied at a given matric potential. Accordingly, as median of grain size $\left(\mathrm{d}_{50}\right)$ increases, less water was retained. At saturation, coarser textures with $\mathrm{d}_{50}>100 \mu \mathrm{m}$ had gravimetric water contents between 20 and $40 \%$, whereas at a matric potential of $-15 \mathrm{kPa}$ the water contents were below $20 \%$. Fine textured soils with $\mathrm{d}_{50}$ between 5 and $20 \mu \mathrm{m}$ had gravimetric water contents around $60 \%$ at saturation, whereas the water content decreased to below $40 \%$ through drainage to $-15 \mathrm{kPa}$ (Fig. 5a and b).

The coefficient of determination $\left(\mathrm{R}^{2}\right)$ between integral $z$ and matric potential under quasi-saturated conditions showed a weak relationship if the textures of all analyzed samples, with varying chemical properties, were considered. However, under saturated conditions the integral $z$ values increases with the median of grain size (Fig. 5c). At a matric potential of $-15 \mathrm{kPa}$ capillary stresses influence the rheological response resulting in larger integral $z$ values. In addition, the integral $z$ values become greater with decreasing median of grain size (Fig. 5d). Consequently, desiccation has a stabilizing effect on the soil microstructure and this effect becomes more distinct the more fine-grained the soil.

\section{Pedotransfer functions}

Due to the considerable impact of particle size distribution, the textures were grouped according to the German soil texture classification (KA5; Ad-Hoc-Arbeitsgruppe Boden (2005)). Based on defined texture groups, the statistical evaluations (ANCOVA, ANOVA) were conducted and the physicochemical

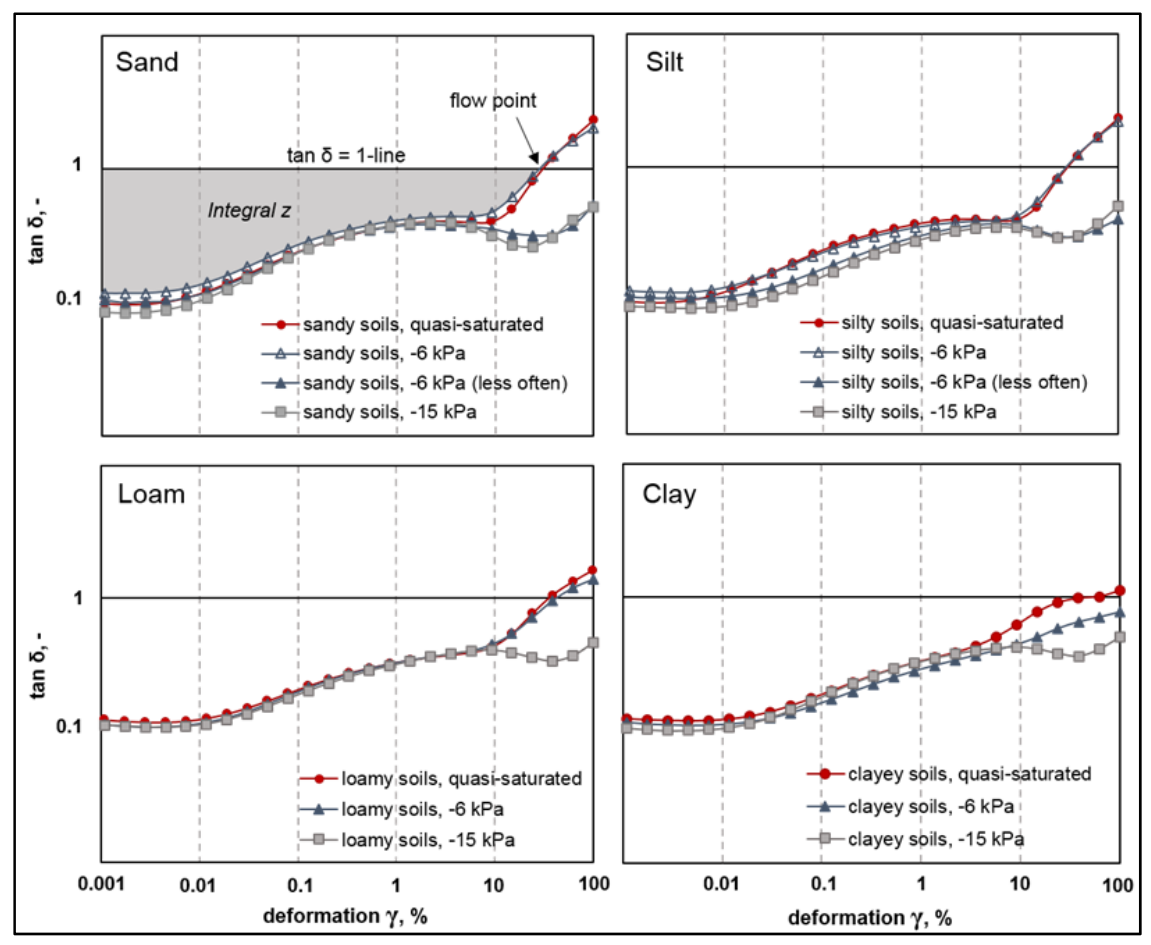

Fig. 4. Generalized graphs for loss factor $(\tan \delta)$ and integral $z$ - quantifying microstructural elasticity - for each studied texture group (sand, loam, silt, clay) and matric potential $(0,-6,-15 \mathrm{kPa})$ portrayed based on representative soil samples and derived from amplitude sweeps under oscillatory and controlled shear deformation. 


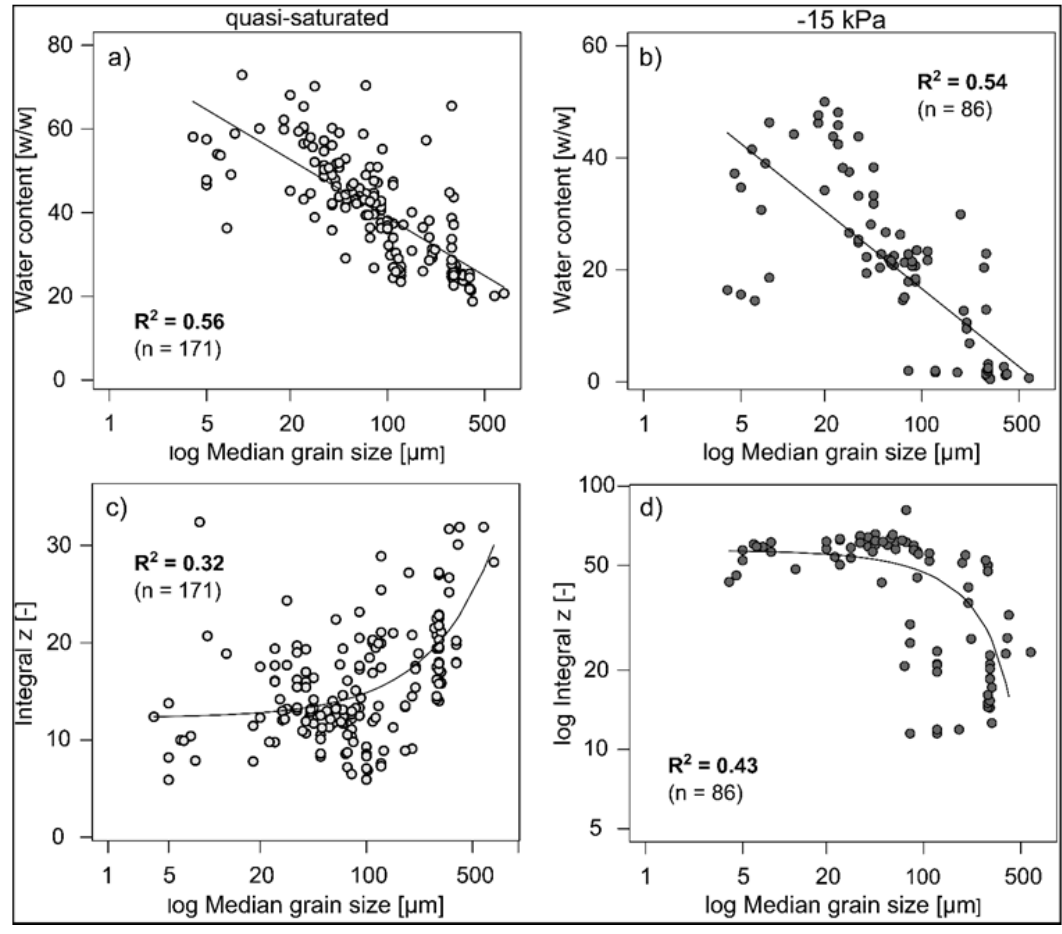

Fig. 5. Texture effect depicted as log median grain size in $\mu \mathrm{m}$ on water content (a and b) and microstructural stiffness (c and d) for different matric potentials (open circles: quasi-saturated, $n=171$; filled circles: $-15 \mathrm{kPa}, \mathrm{n}=86$ ). Single data points indicate the average of five replicates.

Table 4. Pedotransfer functions for mathematical estimation of microstructural stability depending on soil texture.

\begin{tabular}{lll}
\hline Texture group & Pedotransfer function & $\mathrm{R}^{2}$ \\
\hline Sand $(\mathrm{n}=48)$ & integral $z=40.2+3.2 \mathrm{OM}+2.1 \mathrm{Ca}^{2+}+2.7 \mathrm{Fe}_{d}-1.2 \Theta_{g}-0.1$ depth & 0.64 \\
Loam $(\mathrm{n}=25)$ & integral $z=67.9+4.6 \mathrm{OM}+0.2 \mathrm{CaCO}_{3}-1.4 \Theta_{g}$ & 0.56 \\
Silt $(\mathrm{n}=27)$ & integral $z=41.3+6.8 \mathrm{OM}+0.5 \mathrm{CaCO}_{3}+2.3 \mathrm{Fe}_{d}-1.2 \Theta_{g}$ & 0.50 \\
Clay $(\mathrm{n}=15)$ & integral $z=46.7+5.0 \mathrm{OM}+2.3 \mathrm{CaCO}_{3}-3.6 \mathrm{Na}^{+}-0.8 \Theta_{g}-0.2$ depth & 0.62 \\
\hline
\end{tabular}

parameters shown in Table 2 (col. 5) were identified to significantly affect microstructural stability. Electric conductivity was eliminated during model simplification as water-soluble salts did not explain the variance of the integral $z$ values. All other parameters had a significant influence on the elasticity of the soil microstructure.

Additionally, the specific statistical relationships between the rheological parameter integral $z$ and factors influencing microstructural stiffness allowed the development of pedotransfer functions (PTF). These provide a mathematical estimation of the microscale stability parameter integral $z$. The slopes of the relationships between individual parameters and integral $z$ was highly texture dependent, so texture specific PTFs were generated. For reasons of simplicity, those parameters, which have just a minor impact on the soil microstructure, remain unconsidered, if the model quality and accuracy of PTFs does not worsen through their omission. Hence, not every parameter was required for each texture group to predict the integral $z$ value reliably. Table 4 summarizes the developed PTFs for each texture group.

As far as the intersection with the ordinate is concerned, it can be ascertained that the transfer function for loam exhibits the highest intercept, which coincides with the results presented in Table 3, where frequently the largest integral $z$ values were observed in loamy soils. However, organic matter was included in each transfer function, which corroborates its well-known beneficial influence on soil (micro-) structure. Moreover, it is apparent that in sandy soils less organic matter was needed to enhance microstructural stiffness. Likewise the gravimetric water content was included in each function, but with a negative sign indicating its adverse effect (see above). Furthermore, calcite and $\mathrm{Ca}^{2+}$ had a positive effect on elasticity but only one of these parameters was needed in the PTF. Finally pedogenic iron (hydr)oxides had an advantageous impact solely on sand and silt, whereas the detrimental effect of sodium was integrated in the transfer function for clay. It emerged that when the combined effects of the physicochemical parameters were considered, the stabilizing factors were: soil organic matter, concentration of $\mathrm{Ca}^{2+}$, content of $\mathrm{CaCO}_{3}$ and pedogenic iron oxides $\left(F e_{d}\right)$. The concentration of $\mathrm{Na}^{+}$, water content and the depth beneath ground level represented structurally unfavorable factors.

\section{DISCUSSION}

\section{Texture effect}

The loss factor $\tan \delta$, which represents the ratio of viscous to elastic behaviour, can be considered as a measure of the ability to store mechanical energy. Therefore, the capability to retain energy for reversing deformation is greater the smaller the value of $\tan \delta$. Furthermore, it decreases with increasing deformation and a characteristic degradation of internal structure takes place under oscillatory stress, which depends on particle size distribution. The textural effect on the curves of $\tan \delta$ and 
thereby on the absolute value of integral $z$ was already emphasized by Markgraf and Horn (2009) and Baumgarten (2013) and is also evidenced by the results presented here.

Under oscillatory shearing coarse-grained textures initially had a fast reduction of elasticity with increasing deformation. But as a consequence of relative motions (rotation, interlocking, up-piling, reorganization) coarser particles were likely able to attain an energetically more favorable (i.e. more stable) arrangement whereby the complete destruction of microstructure was delayed. While rounded and angular particles exhibit rolling shear behavior (Cho et al., 2006), an increase in platy particles (i.e. clay platelets) leads to a more sliding shear behavior (Smith and Reitsma, 2002), assuming no pronounced aggregation. Sliding shear behavior and the formation of slickensides result in a reduced shear strength ( $\mathrm{Li}$ et al., 2012) caused by depletion of internal structure. Accordingly, the greater the silt and/or clay content, the less often interlocking between particles occurs and elasticity decreases gradually with increasing shear deformation (Baumgarten, 2013). A theoretical consideration of the pore space provides an explanation of why and to what extent the shear behavior on the microscale changes with different particle size distributions. This can be conceptualized by considering a pure sand to which clay is amended at increasing concentrations. At first the contact points between particles in a pure sand remain unchanged after adding a small amount of clay as the clay particles and clusters merely partially occupy the pore space. Increasing the clay content decreases the porosity until the pore space becomes completely filled. Further clay particles are then exclusively deposited between sand particles, so the sand grains become separated and float in the clay matrix, which hence determines the shear behavior (Vallejo and Mawby, 2000).

Moreover, excess pore water pressure may arise under mechanical stress, which reduces effective stress contributed by capillary cohesion. Convex menisci support the displacement of particles relative to one another and therefore deformation of microstructure during shear strain. Depletion and/or redistribution of positive pore water pressure are dependent on hydraulic conductivity, tortuosity of pore space and hydraulic gradient. The reallocation of excess pore water pressures is therefore closely related to particle size distribution and (micro) aggregation of soils: short flow paths and/ or high conductivity favor the reduction of positive pore water pressure. Concave and thus contractive menisci are established when a new equilibrium is reached (Peth et al., 2010).

Finally, in addition to the induced shear behavior, chemical surface properties prevail in clayey soils, because of their smaller particle size. There are diverse clay mineral associations that which react differently to shearing, so the rheological properties may vary substantially. Dolinar and Trauner (2007) found for kaolinite samples saturated with distilled water $(\mathrm{pH} \sim$ 4) a relatively large undrained shear strength due to the opposite charged edges and faces establishing a stable card-house structure. Small amounts of $\mathrm{NaCl}$ induced the collapse of this arrangement, resulting in reduced undrained shear strength through diminished edge-face-attraction and face-facerepulsion and therefore alignment of clay platelets. A similar behavior was observed for Na-smectite suspensions, which also exhibit a greater shear strength at low $\mathrm{pH}$ than at high $\mathrm{pH}$ and high $\mathrm{NaCl}$ concentration based on compressed double layers (Brandenburg and Lagaly, 1988). Furthermore, the authors revealed that in the presence of $\mathrm{Ca}^{2+}$, the attractive forces between edges and faces are enhanced as well as the formation of stable face-face-associations due to a shared double layer. However, it is obvious that the rheological characteristics and degradation of soil microstructure are not exclusively regulated by soil texture. Varying soil chemical features and especially varying water contents affect the rheology of soils as well.

\section{Menisci forces}

The soil microstructure in our study was weakened by increasing water content. Furthermore, the more fine-grained the soil material, the more sensitive it reacted towards shearing under saturated conditions. With increasing saturation, additional water layers were absorbed, which enlarge the distance between individual particles and act as a lubricant. The more water layers that are attached to the mineral surface, the greater the mobility of single particles (Santamarina and Shin, 2009). If chemically active particles are involved, existing interactions are reduced as well capillary suction, i.e. the negative pore water pressure, disappears when complete saturation is reached (Al-Shayea, 2001). Furthermore, because of mechanical strain, positive pore water pressures may occur, promoting the alignment of plate-like particles parallel to the shear direction.

By contrast, increasing desiccation stabilizes the microstructure of soil by water menisci forces, whereby fine-grained soils show a stronger reaction towards dewatering. In unsaturated soils, i.e. at negative pore water pressure, water menisci between soil particles provoke a contractive force such that the matric potential acts as a binding force between particles and stable connections are formed at rest (Osipov, 2014). Therefore, any change in matric potential also causes a change in pore water pressure. By successive drainage, soil particles are pulled together (Horn, 1990) and apparent cohesion increases (Santamarina, 2001), so the resistance of soils against external stresses is enhanced (Kézdi, 1974). Many authors observed the stabilizing effect of menisci forces on the aggregate scale (e.g. Çokça and Tilgen, 2010; Gallipoli et al., 2003; Hoyos et al., 2014). At the microscale the stabilization through menisci forces have also been shown based on various rheological parameters (Baumgarten, 2013; Czibulya et al., 2014; Holthusen et al., 2012b). Ghezzehei and Or (2001) reported an increase of the shear modulus $(\mathrm{G})$ and higher yield stresses with decreasing water content. Markgraf and Horn (2006) observed an enhanced storage modulus $\left(\mathrm{G}^{\prime}\right)$ with reduced water content. Holthusen et al. (2010) determined a higher shear resistance at the end of the linear-viscoelastic range (LVE) as well as higher values for the maximum shear resistance with drainage. On the microscale, the stabilizing effect of desiccation is also related to reduced layers of water molecules. The closer the water molecules to the particle surface, the tighter they are bound to this surface, leading to a lower mobility of the molecules and accordingly to a high viscosity and a higher shear strength of the water films (Israelachvili et al., 1988). Additionally, the decreased distance between particles favors particle-particle interactions (Santamarina and Shin, 2009).

\section{Physicochemical parameters}

The presented results confirm that the microstructure of soils is the product of a multitude of chemical, physical and biological interactions. Considering the combined effect of all relevant physicochemical properties, soil organic matter, concentration of $\mathrm{Ca}^{2+}$, calcite content $\left(\mathrm{CaCO}_{3}\right)$ and pedogenic iron oxides $\left(F_{d}\right)$ represent stabilizing features, whereas the concentration of $\mathrm{Na}^{+}$, water content and the depth beneath ground level were found to be structurally disadvantageous factors. The positive impact of the beneficial factors was mainly attributable to their gluing and cementing effects. Soil organic matter has a marked 
influence on soil structure at different scales and by several mechanisms due to its complexity (Tisdall and Oades, 1982). Extracellular polymeric substances (EPS), metabolites and other breakdown products generated by microbial decomposition act as binding agents, stick soil particles together and improve soil (micro) aggregation (Oades, 1984; Tisdall and Oades, 1982). Another effect of stabilization emerges due to hydrophobization of aggregates: adsorbed hydrophobic organic molecules decrease the wettability and therefore the dispersibility of aggregates (Goebel et al., 2005). The stabilizing effect of organic matter has been thoroughly proven not only on the aggregate scale (e.g. Chenu et al., 2000; De Gryze et al., 2005; Denef et al., 2002; Six et al., 2002), but also on the particleparticle-scale. Holthusen et al. (2012a) examined the impact of organic and mineral fertilization on the rheological behavior of soils from a long-term fertilization trial (Bonn, Germany) and corroborated a decreased sensitivity towards oscillatory shearing with increasing organic matter content. The rheological response of natural slurries was investigated based on rotational experiments by Carotenuto et al. (2015), who reported a decrease in viscosity and yield stress upon the selective removal of soil organic carbon. Majzik and Tombácz (2007) observed an improved microstructure of montmorillonite by adding humic acids ( $\mathrm{pH}$ 6-6.5). However, this strengthening effect was associated with the presence of $\mathrm{Ca}^{2+}$, because otherwise humic acids are bound to the positive charged edges of the clay particles and thus support the dispersion of the microstructure. The importance of the relation between $\mathrm{Ca}^{2+}$ and organic matter was also emphasized by Czibulya et al. (2014).

It is well known, that calcium ions induce the formation of a stable card house structure of clays (Jasmund and Lagaly, 1993) and many authors emphasize the stabilizing effect of $\mathrm{Ca}^{2+}$ (e.g. Paradelo et al., 2013; Wuddivira and Camps-Roach, 2007). Thereby the formation of $\mathrm{Ca}^{2+}$ bridges represents a long-term effect (Six et al., 2004), which is further intensified through the addition of organic substances (Baldock et al., 1994). In this respect, it seems plausible that $\mathrm{Ca}^{2+}$ as well as $\mathrm{CaCO}_{3}$ appeared with a positive sign in the pedotransfer functions, as calcite serves as a $\mathrm{Ca}^{2+}$ source. In addition to its function as a bridging cation, dissolved $\mathrm{Ca}^{2+}$ increases the electrolyte concentration of the soil solution, leading to compressed double layers and diminished dispersibility of clay particles. Chan et al. (2007) ascribed the enhanced soil structure of acid soils after application of $\mathrm{CaCO}_{3}$ to an increase of the electrolyte concentration. Furthermore, $\mathrm{Ca}^{2+}$ may exchange $\mathrm{Na}^{2+}$ and partially $\mathrm{Mg}^{2+}$ at negatively charged exchange sites (Armstrong and Tanton, 1992), because it is preferably bound due to its smaller hydration shell (Zhang and Norton, 2002).

Cementation of mineral particles occurs with an increasing content of iron oxides (Schwertmann and Niederbudde, 1993). Strong interdependencies between iron oxides and organic substances benefit the formation of organo-mineral complexes, which on the one hand stabilize (micro) aggregates and on the other hand soil organic matter (Pronk et al., 2011). Markgraf and Horn (2007) found the development of pseudosand in association with the cementation by iron oxides. Moreover, they described a significant reduction in microstructural stiffness after chemically extracting pedogenic iron oxides from the soils under study.

For clayey soils the pedotransfer function includes sodium with a negative sign, representing the well documented dispersive effect of $\mathrm{Na}^{+}$(e.g. Sumner and Naidu, 1998), which is attributed to its monovalency and its large hydrated radius. Although it is generally known that in natural soils soil moisture is insufficient to completely hydrate exchangeable cations
(Schwertmann and Niederbudde, 1993), $\mathrm{Na}^{+}$-clay-connections are inherently unstable, as $\mathrm{Na}^{+}$mainly forms ionic bonds (Rengasamy and Olsson, 1991). Finally, the water content negatively affects the elasticity of soils: increasing water content weakens the microstructure of soils due to smaller menisci forces as described above.

\section{CONCLUSION}

The rheological analyses of the investigated riparian Marshland soils provide new insight into the dynamic interactions between soil particles and the combined effects of stabilizing and destabilizing factors. The microstructural stiffness of the studied soils was evaluated by amplitude sweeps with controlled shear deformation. The results show a clear dependence on soil texture and water content. Rolling shear behavior in coarse-grained textures may cause a delay of microstructural collapse due to interlocking and/or rotation of soil particles and clusters. In fine-textured soils, sliding shear behaviour predominates and elasticity decreases gradually with increasing deformation. Increasing water content weakens the microstructure of soils due to smaller menisci forces, while desiccation stabilizes the microstructure through amplified menisci forces. The results corroborate the fact that the microstructure of soil is the product of a variety of processes and factors: the factors that significantly affect the soil microstructure in a positive way are soil organic matter, the concentration of $\mathrm{Ca}^{2+}$, calcite content $\left(\mathrm{CaCO}_{3}\right)$ and pedogenic iron oxides $\left(\mathrm{Fe}_{d}\right)$; detrimental factors are the concentration of $\mathrm{Na}^{+}$, water content and the depth beneath ground level. In particular, the consideration of the combined effects of physicochemical features is appropriate to characterize the elasticity of soil microstructure and therefore to develop proper and plausible pedotransfer functions.

Acknowledgements. This study was funded by the Federal Institute of Hydrology (BfG, Koblenz, Germany) and the German Waterways- and Shipping Administration (WSV, in particular Waterways- and Shipping Office, WSA, Hamburg, Germany). We thank Fred Shepherd for proofreading.

\section{REFERENCES}

Ad-Hoc-Arbeitsgruppe Boden, 2005. Bodenkundliche Kartieranleitung. E. Schweizerbart'sche Verlagsbuchhandlung, Stuttgart.

Ajayi Ayodele, E., Horn, R., 2016. Comparing the potentials of clay and biochar in improving water retention and mechanical resilience of sandy soil. Int. Agrophys., 30, 391-399.

Al-Shayea, N.A., 2001. The combined effect of clay and moisture content on the behavior of remolded unsaturated soils. Eng. Geol., 62, 319-342.

Armstrong, A.S.B., Tanton, T.W., 1992. Gypsum applications to aggregated saline sodic clay topsoils. J. Soil Sci., 43, 2, 249-260.

Baldock, J.A., Aoyama, M., Oades, J.M., Susanto, Grant, C.D., 1994. Structural amelioration of a South Australian redbrown earth using calcium and organic amendments. Aust. J. Soil Res., 32, 3, 571-594.

Baumgarten, W., 2013. Soil microstructural stability as influenced by physicochemical parameters and its environmental relevance on multiple scales. Habilitation Thesis, Christian-Albrechts-Universität Kiel.

Baumgarten, W., Dörner, J., Horn, R., 2013. Microstructural development in volcanic ash soils from South Chile. Soil Tillage Res., 129, 48-60. 
Baumgarten, W., Neugebauer, T., Fuchs, E., Horn, R., 2012. Structural stability of Marshland soils of the riparian zone of the Tidal Elbe River. Soil Tillage Res., 125, 80-88.

Bergemann, M., 1995. Die Lage der oberen Brackwassergrenze im Elbeästuar. Deutsche Gewässerkundliche Mitteilungen, 39, 4-5, 134-137.

Blume, H.-P., Stahr, K., Leinweber, P., 2011. Bodenkundliches Praktikum. Eine Einführung in pedologisches Arbeiten für Ökologen, insbesondere Land- und Forstwirte, und für Geowissenschaftler. Spektrum Akademischer Verlag, Heidelberg.

Brandenburg, U., Lagaly, G., 1988. Rheological properties of sodium montmorillonite dispersions. Appl. Clay Sci., 3, 3, 263-279.

Bronick, C.J., Lal, R., 2005. Soil structure and management: a review. Geoderma, 124, 1-2, 3-22.

Carotenuto, C., Merola, M.C., Álvarez-Romero, M., Coppola, E., Minale, M., 2015. Rheology of natural slurries involved in a rapid mudflow with different soil organic carbon content. Colloid Surface A, 466, 57-65.

Chan, K.Y., Conyers, M.K., Scott, B.J., 2007. Improved structural stability of an acidic hardsetting soil attributable to lime application. Commun Soil Sci. Plan., 38, 15-16, 21632175.

Chenu, C., Le Bissonnais, Y., Arrouays, D., 2000. Organic matter influence on clay wettability and soil aggregate stability. Soil Sci. Soc. Am. J., 64, 4, 1479-1486.

Cho, G.C., Dodds, J., Santamarina, J.C., 2006. Particle shape effects on packing density, stiffness, and strength: Natural and crushed sands. Journal of Geotechnical and Geoenvironmental Engineering, 132, 5, 591-602.

Çokça, E., Tilgen, H.P., 2010. Shear strength-suction relationship of compacted Ankara clay. Appl. Clay Sci., 49, 4, 400-404.

Czibulya, Z., Szegi, T., Michéli, E., Tombácz, E., 2014. Rheological measurements for indicating structural changes in selected soil catenas of European experimental fields. Int. J. Agric. Sci. Technol., 2, 1, 22-31.

De Gryze, S., Six, J., Brits, C., Merckx, R., 2005. A quantification of short-term macroaggregate dynamics: influences of wheat residue input and texture. Soil Biol. Biochem., 37, 1, 55-66.

Denef, K., Six, J., Merckx, R., Paustian, K., 2002. Short-term effects of biological and physical forces on aggregate formation in soils with different clay mineralogy. Plant Soil, 246, 2, 185-200.

Dolinar, B., Trauner, L., 2007. The impact of structure on the undrained shear strength of cohesive soils. Eng. Geol., 92, $1-2,88-96$.

Freitag, C., Hochfeld, B., Ohle, N., 2007. Lebensraum Tiedeelbe. Coastline Reports, 9, 69-79.

Gallipoli, D., Gens, A., Sharma, R., Vaunat, J., 2003. An elasto-plastic model for unsaturated soil incorporating the effects of suction and degree of saturation on mechanical behaviour. Geotechnique, 53, 9, 844-844.

Garniel, A., Mierwald, U., 1996. Changes in the morphology and vegetation along the human-altered shoreline of the Lower Elbe. In: Nordstrom, K.F., Roman, C.T. (Eds.): Estuarine Shores: Evolution, Environments and Human Alterations. John Wiley \& Sons Ltd., New York, USA, pp. 375-396.

Ghezzehei, T.A., Or, D., 2001. Rheological properties of wet soils and clays under steady and oscillatory stresses. Soil Sci. Soc. Am. J., 65, 3, 624-637.

Goebel, M.O., Bachmann, J., Woche, S.K., Fischer, W.R., 2005.
Soil wettability, aggregate stability, and the decomposition of soil organic matter. Geoderma, 128, 1-2, 80-93.

Hartge, K.H., Horn, R., 2016. Essential Soil Physics. An Introduction to Soil Processes, Functions, Structure and Mechanics. Schweizerbart, Stuttgard, 389 p.

Holthusen, D., 2010. Fertilization induced changes in soil stability at the microscale revealed by rheometry. Dissertation Thesis. Christian-Albrechts-Universität Kiel.

Holthusen, D., Peth, S., Horn, R., 2010. Impact of potassium concentration and matric potential on soil stability derived from rheological parameters. Soil Tillage Res., 111, 1, 7585.

Holthusen, D., Jänicke, M., Peth, S., Horn, R., 2012a. Physical properties of a Luvisol for different long-term fertilization treatments II. Microscale behavior and its relation to the mesoscale. J. Plant Nutr. Soil Sci., 175, 1, 14-23.

Holthusen, D., Peth, S., Horn, R., Kuhn, T., 2012b. Flow and deformation behavior at the microscale of soils from several long-term potassium fertilization trials in Germany. J. Plant Nutr. Soil Sci., 175, 4, 535-547.

Holthusen, D., Reeb, D., Horn, R., 2012c. Influence of potassium fertilization, water and salt stress, and their interference on rheological soil parameters in planted containers. Soil Tillage Res., 125, 72-79.

Horn, R., 1990. Aggregate characterization as compared to soil bulk properties. Soil Tillage Res., 17, 3-4, 265-289.

Hoyos, L.R., Velosa, C.L., Puppala, A.J., 2014. Residual shear strength of unsaturated soils via suction-controlled ring shear testing. Eng. Geol., 172, 1-11.

Israelachvili, J.N., Mcguiggan, P.M., Homola, A.M., 1988. Dynamic properties of molecularly thin liquid-films. Science, 240, 4849, 189-191.

Jasmund, K., Lagaly, G., 1993. Tonminerale und Tone. Struktur, Eigenschaften, Anwendung und Einsatz in Industrie und Umwelt. Steinkopff Verlag, Darmstadt.

Jeong, S.W., Locat, J., Leroueil, S., Malet, J.P., 2010. Rheological properties of fine-grained sediment: the roles of texture and mineralogy. Canadian Geotechnical Journal, 47, $10,1085-1100$.

Kézdi, Á., 1974. Handbook of Soil Mechanics, Vol. 1: Soil Physics. Elsevier, Amsterdam.

Laird, N.M., Ware, J.H., 1982. Random-effects models for longitudinal data. Biometrics, 38, 4, 963-974.

Li, Y.R., Aydin, A., Xu, Q., Chen, J., 2012. Constitutive behavior of binary mixtures of kaolin and glass beads in direct shear. KSCE J. Civ. Eng., 16, 7, 1152-1159.

Majzik, A., Tombácz, E., 2007. Interaction between humic acid and montmorillonite in the presence of calcium ions I. Interfacial and aqueous phase equilibria: Adsorption and complexation. Org Geochem, 38, 8, 1319-1329.

Markgraf, W., 2006. Microstructural changes in soils. rheological investigations in soil mechanics. Dissertation Thesis. Christian-Albrechts-Universität Kiel.

Markgraf, W., Horn, R., 2006. Rheological-stiffness analysis of $\mathrm{K}^{+}$-treated and $\mathrm{CaCO}_{3}$-rich soils. J. Plant Nutr. Soil. Sci., 169, 3, 411-419.

Markgraf, W., Horn, R., 2007. Scanning electron microscopyenergy dispersive scan analyses and rheological investigations of south-Brazilian soils. Soil Sci. Soc. Am. J., $71,3,851-859$.

Markgraf, W., Horn, R., 2009. Rheological investigations in soil micro mechanics: Measuring stiffness degradation and structural stability on a particle scale. In: Gragg, L.P., Cassell, J.M. (Eds.): Progress in Management Engineering. Nova Science Publishers, Inc., New York, pp. 237-279. 
Markgraf, W., Horn, R., Peth, S., 2006. An approach to rheometry in soil mechanics - Structural changes in bentonite, clayey and silty soils. Soil Till. Res., 91, 1-2, 1-14.

Markgraf, W., Moreno, F., Horn, R., 2012a. Quantification of microstructural changes in Salorthidic Fluvaquents using rheological and particle charge techniques. Vadose Zone J., 11, 1. DOI:10.2136/vzj2011.0061.

Markgraf, W., Watts, C.W., Whalley, W.R., Hrkac, T., Horn, R., 2012b. Influence of organic matter on rheological properties of soil. Appl. Clay Sci., 64, 25-33.

Mehra, O.P., Jackson, M.L., 1960. Iron oxide removal from soils and clays by a dithionite-citrate system buffered with sodium bicarbonate. Clay Clay Miner., 7, 317-327.

Mezger, T.G., 2014. The Rheology Handbook: For Users of Rotational and Oscillatory Rheometers. Vincentz Network, Hannover, Germany.

Oades, J.M., 1984. Soil organic-matter and structural stability Mechanisms and implications for management. Plant Soil, 76, 1-3, 319-337.

Osipov, V.I., 2014. Physicochemical theory of effective stresses in soils. Water Resources, 41, 7, 801-818.

Paradelo, R., van Oort, F., Chenu, C., 2013. Water-dispersible clay in bare fallow soils after 80 years of continuous fertilizer addition. Geoderma, 200, 40-44.

Pértile, P., Reichert, J.M., Gubiani, P.I., Holthusen, D., Costa, A.d., 2016. Rheological parameters as affected by water tension in subtropical soils. Rev. Bras. Cienc. Solo, 40, e0150286.

Peth, S., Rostek, J., Zink, A., Mordhorst, A., Horn, R., 2010. Soil testing of dynamic deformation processes of arable soils. Soil Tillage Res., 106, 2, 317-328.

Pronk, G.J., Heister, K., Kogel-Knabner, I., 2011. Iron oxides as major available interface component in loamy arable topsoils. Soil Sci. Soc. Am. J., 75, 6, 2158-2168.

R Developement Core Team, 2013. R: A language and environment for statistical computing.

Rengasamy, P., Olsson, K.A., 1991. Sodicity and soil structure. Aust. J. Soil Res., 29, 6, 935-952.

Santamarina, J.C., 2001. Soil behavior at the microscale: Particle forces. In: Proceedings of the Symposium of Soil Behavior and Soft Ground Construction, in honor of Charles C. Ladd. MIT, pp. 1-32.

Santamarina, J.C., Shin, H., 2009. Friction in granular media. In: Hatzor, Y.H., Sulem, J., Vardoulakis, I. (Eds.): MesoScale Shear Physics in Earthquake and Landslide Mechanics. CRC Press, Boca Raton, London.

Schlichting, E., Blume, H.-P., Stahr, K., 1995. Bodenkundliches Praktikum. Eine Einführung in und
Forstwirte und für Geowissenschaftler. Blackwell Wissenschafts-Verlag, Berlin, Wien.

Schwertmann, U., Niederbudde, E.-A., 1993. Tonminerale in Böden. In: Jasmund, K., Lagaly, G. (Eds.): Tonminerale und Tone. Struktur, Eigenschaften, Anwendungen und Einsatz in Industrie und Umwelt. Steinkopff Verlag, Darmstadt, pp. 212-265.

Six, J., Feller, C., Denef, K., Ogle, S.M., Sa, J.C.D., Albrecht, A., 2002. Soil organic matter, biota and aggregation in temperate and tropical soils - Effects of no-tillage. Agronomie, 22, 7-8, 755-775.

Six, J., Bossuyt, H., Degryze, S., Denef, K., 2004. A history of research on the link between (micro)aggregates, soil biota, and soil organic matter dynamics. Soil Till. Res., 79, 1, 7-31.

Smith, D.W., Reitsma, M.G., 2002. Towards an explanation for the residual friction angle in montmorillonite clay soils. In: Vulliet, L., Laloui, L., Schrefler, B. (Eds.): Environmental Geomechanics. EPFL/ Centre Midi, Lausanne, Schweiz, pp. $27-44$.

Stoppe, N., Horn, R., 2017. How far are rheological parameters from amplitude sweep tests predictable using common physicochemical soil properties? IOP Conference Series: Journal of Physics: Conference Series, 790(1)012032.

Sumner, M.E., Naidu, R., 1998. Sodic Soils: Distribution, Properties, Management and Environmental Consequences. Oxford University Press Inc., New York.

Tisdall, J.M., Oades, J.M., 1982. Organic matter and waterstable aggregates in soils. J. Soil Sci., 33, 2, 141-163.

Torrance, J.K., 1999. Physical, chemical and mineralogical influences on the rheology of remoulded low-activity sensitive marine clay. Appl. Clay Sci., 14, 4, 199-223.

Vallejo, L.E., Mawby, R., 2000. Porosity influence on the shear strength of granular material-clay mixtures. Eng. Geol., 58, $2,125-136$.

Verbeke, G., Molenberghs, G., 2008. Linear Mixed Models for Longitudinal Data. Springer Verlag, New York.

Warkentin, B.R., 2008. Soil structure: A history from tilth to habitat. Adv. Agron., 97, 239-272.

Wuddivira, M.N., Camps-Roach, G., 2007. Effects of organic matter and calcium on soil structural stability. Eur. J. Soil Sci., 58, 3, 722-727.

Zhang, X.C., Norton, L.D., 2002. Effect of exchangeable Mg on saturated hydraulic conductivity, disaggregation and clay dispersion of disturbed soils. J. Hydrol., 260, 194-205.

Received 2 November 2016 Accepted 16 May 2017 